\title{
The Need of Vitamin D Supplementation Programme in India
}

\author{
Vivek Dixit ${ }^{1}$, James Pegrum², Dinesh K Dhanwal ${ }^{3}$, Sahil Batra ${ }^{4}$, Bhavuk Garg ${ }^{5}$
}

\section{Purpose}

With the aim to alleviate the vitamin D deficiency in Indian population for the achievement of better bone health on the path of holistic health approach.

\section{Background \& Introduction}

Vitamin $D$ is unique as it is both a nutrient and hormone that provides wide variety of health benefits to human health. The health benefits of vitamin $D$ are beyond bone heath confirmed from various studies viz vitamin $D$ not only regulate calcium metabolism but also regulates insulin production, reduces the risk of diabetes and cancer, rennin production, helps in destruction of infectious agents, regulation of cell growth, enhances immunity, maintenance of vascular tone of the body, myocardial function and helps in many more complex diseases as well. Recently, Vitamin D has received enormous attention worldwide and referred as drug of the decade when its deficiency referred pandemic [1]. The quantum of problem can be understood by looking at its (vitamin D) deficiency in Indian subcontinent with a prevalence rate between 70 to $100 \%$ [2].

Several studies have seen the result of vitamin D supplementation including improvement in handgrip strength [3] increased newborn's length in pregnant women [4]. Vitamin D supplementation shown reduces risk of maternal co morbidities and helps improve neonatal outcomes [5].Vitamin D requirements are probably greater in pregnancy, as evidenced by physiologically higher 1,25-dehydroxy vitamin D levels seen in the second and third trimesters. Studies recommend that vitamin $D$ should continue to supplement in all pregnant women from the $12^{\text {th }}$ week of gestation onwards. The results suggest a safest dose to adhere to $4000 \mathrm{IU} /$ day as a standard practice [6].

Whether vitamin D supplementation in pre-diabetes subjects prevents the development of diabetes is a matter of debate as the results from the available studies are inconsistent. However, a short-term vitamin $D$ supplementation was found helpful in the decline of residual beta cell function (RBCF) in children with type 1 diabetes [7]. Effect of 12 months of vitamin $D$ supplementation on glycemic parameters and progression of pre-diabetes to diabetes in an ethnically homogeneous Kashmiri population showed significant lowering in FPG, 2-h plasma glucose and A1C levels [8]. Study on healthy subjects also shown beneficial effect that were supplemented with cholecalciferol at a dose of 60,000 IU/week for 12 weeks resulted in improvement in the skeletal muscle energy metabolism[9]. Indian studies regarding vitamin D supplementation including pregnant women [10], Young women [11] and Asian Indians [12] already shown beneficial effect. However, randomized controlled trials provide some low-quality evidence to support vitamin $D$ supplementation in asthma [13], acute respiratory infections (ARI) [14] and in improving insulin resistance as well [15].

${ }^{1}$ Department of Orthopedics, All India Institute of Medical Sciences, New Delhi, India.

${ }^{2}$ Nuffield Orthopedics Centre, University of Oxford, UK.

${ }^{3} \mathrm{NMC}$ Super Specialty Hospital, Abu Dhabi, UAE.

${ }^{4} J u n i o r$ Resident, ${ }^{5}$ Associate Professor, Orthopedics, AlIMS.

Correspondence: Dr. Vivek Dixit, Department of Orthopedics, All India Institute of Medical Sciences, New Delhi, India.

E-mail Id: vivek_sgpgi@yahoo.com

Orcid Id: http://orcid.org/0000-0002-3448-1856

How to cite this article: Dixit V, Pegrum J, Dhanwal DK et al. The Need of Vitamin D Supplementation Programme in India. J Adv Res Med 2017; 4(3\&4): 5-7.

Digital Object Identifier (DOI): https://doi.org/10.24321/2349.7181.201702 
The advocacy for vitamin D supplementation would not have been done only for populations are at risk for developing vitamin D deficiency; sensible sun exposure is an inexpensive and enjoyable way to maintain vitamin $D$ stores. It seems a paradox where majority of population is vitamin D deficient living in sunny country. Reasons to this problem are many including environmental (latitude \& altitude), clothing pattern, higher melanin content, food habits and genetic factors [16].

Fortification of food products In India is rare. According to recommended dietary allowance (RDA), should meet the need of majority of the population. Therefore, an additional intake of vitamin $D$ needed either through supplements or fortified foods. Foods fortified with vitamin D usually contain $100 \mathrm{IU}$ per serving. Consumption of vitamin $D$ fortified foods; especially milk has shown a significant improvement in $25(\mathrm{OH}) \mathrm{D}$ levels. Even though, fortification has many practical issues including the choice of product, how much to fortify to be enough! Logistics of fortification and monitoring is a challenge too. Developed countries like USA and Canada have started fortification of milk with vitamin D in 1930s. Recent studies suggest the fortification of vitamin $D$ through staple food may be a viable strategy to meet up vitamin $D$ deficiency especially in children [2]. According to Institute of Medicine (IOM), the recommended intake of vitamin D should be $600 \mathrm{IU} /$ day for all individuals (1-70 years), appears insufficient to meet vitamin D sufficiency ( $\geq 30 \mathrm{ng} / \mathrm{mL}$ ) [17]. Let's assume, if the typical serum $25(\mathrm{OH}) \mathrm{D}$ levels in average Indian is 10 $\mathrm{ng} / \mathrm{ml}$ and the target serum $25(\mathrm{OH}) \mathrm{D}$ levels is around 30 $\mathrm{ng} / \mathrm{ml}$, then the requirement would be at least $2000 \mathrm{IU} /$ day. However, recent studies suggest the vitamin $D$ intake to attain a desired serum $25(\mathrm{OH}) \mathrm{D}$ status required a dose of 4000 units/day [18].

However, $1000 \mathrm{IU}$ of vitamin D/day has shown better results than 60, $000 \mathrm{IU} /$ week in populations but it will be difficult to feed $1000 \mathrm{IU} /$ Day to populations due to logistics issues. In clinical practice, a dose of 60,000 IU/week initially for 8 weeks and then limiting for once a month commonly seen as prophylactic doses schedule in populations to acquire optimal status of vitamin D [19]. It is equally important to monitor vitamin $\mathrm{D}$ levels in body through periodic blood check-up while supplementation to monitor the vitamin D toxicity. It would be appreciable if the voluntary testing of vitamin $D$ in government hospitals to be tested for free in similar fashion likes ongoing voluntary HIV and diabetes testing. This voluntary testing of vitamin D will be helpful in population to keep updated about their bone health.

Ongoing studies encourage improving the knowledge, awareness and attitude towards vitamin D especially in young generation [20]. Needless to say, a wide publicity and advocacy of vitamin D supplementation programme from civil societies with the help of government will be an appreciable step. Likewise the success of previous major supplementation programes in India such as iron-folic acid supplementation; iodine fortification and vitamin A supplementation programme, it will be good to have fortified food products to boost bone health of population. This approach will not only help to optimize the vitamin D deficiency but also help to mitigate the growing burden of communicable and non-communicable diseases as well. Moreover, while implementing the Vitamin D supplementation/fortification programme as a public health initiative; the diversity in Indian population should be kept into consideration thus requires a careful selection of target population in the community.

\section{Conflict of Interest: None}

\section{References}

1. Hossein-nezhad A, Holick MF. Vitamin D for health: A global perspective. Mayo Clin Proc. 2013;88(7):720-55.

2. Ritu G and Ajay Gupta. Vitamin D Deficiency in India: Prevalence, Causalities and Interventions. Nutrients.2014; 6(2): 729-775.

3. Cavalcante R, Maia J, Mesquita P, Henrique R, Griz L, Bandeira MP, Bandeira F. The effects of intermittent vitamin D3 supplementation on muscle strength and metabolic parameters in postmenopausal women with type 2 diabetes: a randomized controlled study. The Adv Endocrinol Metab. 2015;6(4):149-54.

4. Asemi Z, Esmaillzadeh A. The Effect of Multi mineralVitamin D Supplementation on Pregnancy Outcomes in Pregnant Women at Risk for Pre-eclampsia. Int J Prev Med. 2015;13:6:62.

5. Sablok A, Batra A, Thariani K, Batra A, Bharti R, Aggarwal $A R$, Kabi BC, Chellani H. Supplementation of vitamin $D$ in pregnancy and its correlation with feto-maternal outcome. Clin Endocrinol (Oxf). 2015;83(4):536-41.

6. Mithal A and Kalra S. Vitamin D supplementation in pregnancy.Indian J EndocrinoIMetab. 2014;18(5):593596.

7. Mishra A, Dayal D, Sachdeva N, Attri SV. Effect of 6-months' vitamin D supplementation on residual beta cell function in children with type 1 diabetes: a case control interventional study. J Pediatr Endocrinol Metab. 2016;29(4):395-400.

8. Kuchay MS, Laway BA, Bashir MI, Wani Al, Misgar RA, Shah ZA.Effect of Vitamin D supplementation on glycemic parameters and progression of prediabetes to diabetes: A 1-year, open-label randomized study. Indian J Endocrinol Metab. 2015;19(3):387-92.

9. Rana P, Marwaha RK, Kumar P, Narang A, Devi MM, Tripathi RP, Khushu S. Effect of vitamin D supplementation on muscle energy phosphometabolites: $\mathrm{a}^{31} \mathrm{P}$ magnetic resonance spectroscopybased pilot study. Endocr Res. 2014; 39(4):152-6.

10. Sahu M, Das V, Aggarwal A, Rawat V, Saxena P, Bhatia 
V. Vitamin D replacement in pregnant women in rural north India: a pilot study. Eur J ClinNutr.2009; 63(9):1157-9.

11. Malhotra N, Mithal A, Gupta S, Shukla M, Godbole M. Effect of vitamin D supplementation on bone health parameters of healthy young Indian women. Arch Osteoporos. 2009; 4(1-2):47-53.

12. Goswami R, Gupta N, Ray D, Singh N, Tomar N. Pattern of 25-hydroxy vitamin $D$ response at short ( 2 month) and long (1 year) interval after 8 weeks of oral supplementation with cholecalciferol in Asian Indians with chronic hypovitaminosis D.Br J Nutr. 2008; 100(3):526-9.

13. Riverin BD, Maguire JL, Li P. Vitamin D Supplementation for Childhood Asthma: A Systematic Review and MetaAnalysis. PLoS One. 2015; 31:10(8).

14. Xiao L, Xing C, Yang Z, Xu S, Wang M, Du H, Liu K, Huang Z. Vitamin D supplementation for the prevention of childhood acute respiratory infections: a systematic review of randomised controlled trials. $\mathrm{Br} J$ Nutr. 2015;27:1-9.

15. Poolsup N, Suksomboon N, Plordplong N. Effect of vitamin D supplementation on insulin resistance and glycaemic control in prediabetes: a systematic review and meta-analysis. Diabet Med. 2016; 33(3):290-9.

16. Mithal A et al. Global vitamin D status and determinants of hypovitaminosis D.Osteoporos Int. 2009;20(11):1821.

17. Heaney R.P., Holick M.F. Why the IOM recommendations for vitamin D are deficient. J. Bone Miner Res. 2011;26:455-457.

18. Aloia et al, African Americans, 25-hydroxyvitamin D, and osteoporosis: a paradox. Am J ClinNutr. 2008;88(2):545S-550S.

19. Haines ST, Park SK. Vitamin D supplementation: what's known what to do, and what's needed? Pharmacotherapy. 2012; 32(4):354-82.

20. Harsh arora, Vivek Dixit, Nidhi Srivastava. Evaluation of knowledge, practices of vitamin $d$ and attitude toward sunlight among Indian students. Asian Journal of pharmaceutical and clinical research. 2016;9:308313.

Date of Submission: 2017-07-13

Date of Acceptance: 2017-08-14 